\title{
COMPARATIVE EVALUATION OF BIOACTIVE MATERIALS AND THEIR NANO-COUNTERPART AS PULP CAPPING AGENTS IN DOGS' TEETH
}

\author{
Dalia M Fayyad* and Ghada A ElBaz**
}

\begin{abstract}
Introduction: Direct pulp-capping is an alternative procedure to extraction or endodontic therapy, in which a medicament is placed directly over the exposed pulp to maintain pulp vitality and facilitate the formation of protective barrier. Aim of study: The purpose of this study was to evaluate and compare the histological response of dog's pulp after direct pulp capping with 3 different materials; MTA, Bioactive glass, CEM and their nanoparticles, at 1 month and 3 month time intervals.
\end{abstract}

Materials \& Methods: A total of 112 teeth in 8 dogs were used for this study, where 96 teeth were pulp capped with the investigated materials and 16 teeth were serving as negative control. The 14 teeth of each dog were classified into 6 experimental groups and one control (2 teeth each) as follows: Group A: was capped with MTA, Group B: was capped with NMTA, Group C: was capped with CEM, Group D: was capped with NCEM, Group E: was capped with Bioactive glass, Group F: was capped with Nano Bioactive glass and Group G: unprepared tooth (negative control). Dogs were randomly divided into 2 groups ( 4 dogs each), relative to the observation periods tested, 1 month and 3 months for histomorphological evaluation of pulp response after direct pulp capping with tested materials.

Results: Regarding the dentin bridge formation, both NMTA and NCEM groups induced thick dentin bridge with irregular dentin pattern in 1 and 3 months evaluation time period while MTA and CEM induced thinner dentin bridge with regular dentin pattern. BG and NBG groups showed the lowest mean dentin bridge thickness values with no tubular dentin pattern. About the inflammatory reaction of the dental pulp to materials with conventional particle size; MTA displayed the highest prevalence of no inflammation followed by CEM while BG showed the highest prevalence of moderate inflammation and the highest inflammatory cell counts. All nanomaterials showed the highest mean inflammatory cell counts at both evaluations time periods.

Conclusion: MTA and CEM can be considered favorable materials for direct pulp capping, while BG and NBG produced the worst inflammatory cell reaction, dentin bridge thickness and quality. Nanoparticles although increased dentin bridge thickness, they also increased the inflammatory cell reaction.

* Associate Professor of Endodontics, Faculty of Dentistry, Suez Canal University .

** Assistant Professor of Pediatric and Preventive Dentistry and Dental Public Health, Faculty of Dentistry, Suez Canal University 


\section{INTRODUCTION}

Direct pulp-capping (DPC) technique is a welldocumented vital pulp therapy for exposed vital pulp in which a dressing material is used to cover the injured area to facilitate the formation of a hard tissue protective barrier ${ }^{(1,2)}$ and the maintenance of pulp vitality ${ }^{(3)}$. Accordingly, direct pulp-capping has been used as an alternative approach to many of definitive root canal treatments ${ }^{(4)}$. Pulp capping can be considered as a proper technique especially in the treatment of young permanent teeth with traumatic injuries ${ }^{(5,6)}$. Pulp capping procedure in young patients has a higher success rate than in adult patients, this finding might be attributed to the higher capacity of the pulp of young teeth in responding to different insults and their rich apical perfusion $^{(7,8)}$.

As the bacterial attack is the most cause of failure of DPC, the provision of an adequate seal against bacterial (re)entry is an important factor in the success of vital pulp therapy ${ }^{(9)}$. Therefore, an effective pulp capping material should be biocompatible, prevent bacterial leakage, provide a biological seal and stimulate differentiation of odontoblast cells to allow regeneration of the pulpdentin complex ${ }^{(10)}$. Nevertheless, many products are available in the market, yet the most suitable pulp capping material is not found ${ }^{(11)}$.

Numerous studies stated that MTA prompted a more probable hard tissue barrier formation and a less pulpal inflammation when compared with the hard setting calcium hydroxide ${ }^{(12)}$ as a pulp capping materials. MTA is mainly a silicate cement mixture in the form of tricalcium silicate, dicalcium silicate and tricalcium aluminate. Calcium hydroxide, which is the primary reaction product of MTA with water, can be considered the main cause of the high biocompatibility of MTA. Both MTA and calcium hydroxide have proper biocompatibility and antibacterial properties and similar ability to release of bioactive dentin matrix proteins. Moreover, MTA has a good seal to tooth structure rather than calcium hydroxide, it is used as a common biomaterial for different endodontic procedures including; vital pulp therapy, regeneration, repair of root perforations, apexification and root end filling ${ }^{(13)}$.

Bioactive glass (BG), calcium sodium phosphosilicate, is currently regarded as the most biocompatible material in the bone regeneration field due to its high biocompatibility and remarkable bioactive capability in forming apatitelike structure ${ }^{(14)}$. Moreover, the ionic degradation products, especially silica species, have shown osteoinductive and angiogenesis properties ${ }^{(15,16)}$. In addition, it has the ability to induce hard tissue formation and mineralization ${ }^{(17)}$, bioactive glass can be considered as a material of choice for pulp capping and periapical bone healing.

On the other hand, Calcium-enriched mixture (CEM) is a hydrophilic cement that contains many calcium compounds including oxides and hydroxides (for example, calcium oxide and calcium hydroxide $[\mathrm{CH}]$ ), calcium phosphate, and calcium silicate with similar clinical applications to $\mathrm{MTA}^{(18,19)}$. CEM has biocompatible and antimicrobial properties ${ }^{(20)}$. It enhances HA crystals formation ${ }^{(21)}$ so it was used for the treatment of furcal perforation in the primary teeth $^{(22)}$ and for DPC in primary and permanent teeth $^{(23)}$. It was stated that CEM seems to be suitable for DPC as it has favorable properties and effects on human dental pulp ${ }^{(24)}$.

Recently, Nanotechnology has been used on a large scale in the field of dentistry. Many studies have confirmed that nanoparticles have better bioactivity and higher ability to enhance dentine mineralization process compared to normal sized particles ${ }^{(25,26)}$. It was also found that nanoparticles exhibit better mechanical properties, due to increased surface area of the nanoparticles, as improved sinterability and enhanced densification which may improve fracture toughness ${ }^{(27)}$. Moreover, because of their minute size, nanoparticles are more able to penetrate into dentinal tubules and improve the poor adhesion 
qualities of different dental pulp capping materials compared to normal sized particles ${ }^{(28)}$.

Studies comparing MTA, BG, and CEM in terms of vital pulp treatment behavior are rather limited. Therefore, this study was conducted to evaluate and compare the histological response of dog's pulp after direct pulp capping with 3 different materials; MTA, Bioactive glass, CEM and their nanoparticles, at 1 month and 3 month time intervals.

\section{MATERIAL AND METHODS}

This study was carried out in 8 Mongrel dogs at the age 1.5 years old and with an average weight of $25 \mathrm{~kg}$ with permanent dentition. Dogs were starved for 12-24 hours and thirsted for 6 hours prior to anesthesia. Each animal was sedated with subcutaneous injection of an anti-cholinergic drug (Atropine sulphate) 10-30 minutes before the operations in a dose of $0.05 \mathrm{mg} / \mathrm{kg}$ body weight. General anesthesia was induced with an intramuscular injection of a mixture of Xylazine $\mathrm{HCl} 1 \mathrm{mg} / \mathrm{Kg}$ body weight and Ketamine $\mathrm{HCl}$ $5 \mathrm{mg} / \mathrm{kg}$.

\section{Selection and grouping of experimental teeth (samples)}

A total of 112 teeth were used for this study, where 96 teeth were pulp capped with the investigated materials and 16 teeth were serving as negative control (14 teeth /dog; 6 anterior teeth and 1 canine/ arch). The 14 teeth of each dog were classified into 6 experimental groups and one control (2 teeth each), provided that all tested materials were presented in each arch of each dog as follows:

Group A: was capped with MTA (ProRoot; Dentsply Tulsa Dental, OK, USA).

Group B: was capped with nano MTA (NMTA) [obtained by grinding of MTA in a zirconia ball-mill machine for $24 \mathrm{~h}$ (Raymer Engineering Mazgaon road, Mumbai, India).

Group C: was capped with CEM (Bionique Dent-Iran).
Group D: was capped with nano CEM (NCEM) [obtained by grinding of CEM in a zirconia ball-mill machine for $24 \mathrm{~h}$ (Raymer Engineering Mazgaon road, Mumbai, India).

Group E: was capped with Bioactive glass (BG)

Group F: was capped with Nano Bioactive glass $(\mathrm{NBG})\left(\mathrm{SiO}_{2}-\mathrm{CaO}-\mathrm{P}_{2} \mathrm{O}_{5}(\mathrm{~mol} \%)=55: 40: 5\right)$.

Both BG and NBG were prepared via a threestep sol-gel method ${ }^{(29)}$ at the College of Pharmacy, Suez Canal University, Ismailia, Egypt).

Group G: unprepared tooth (negative control)

Dogs were randomly subdivided into 2 subgroups (4 dogs each), relative to the observation periods tested, 1 month and 3 months.

\section{Cavity preparation and pulp exposure:}

Prior to the operative procedure, teeth were cleaned and polished with pumice paste to remove plaque and calculus. The operating field was disinfected with an antiseptic solution. Then anterior teeth were isolated by a rubber dam and labial class $\mathrm{V}$ cavities were prepared $1 \mathrm{~mm}$ above the gingival margin (approximately $3 \times 5 \mathrm{~mm}$ ) with a high-speed contra-angle working at $30000 \mathrm{rpm}$ (TC Motor 3000 , France). Round carbide burs (size $0.6 \mathrm{~mm}$; Maillefer, France) were used with copious sterile water spray. A new bur was used every four teeth to ensure cutting efficiency. The finished cavities were prepared with proper undercuts at the line angles to retain the capping and filling material.

The pulpal floors of the prepared cavities were finished as close as possible to the pulps until the pink shadow of the pulp becomes apparent, leaving a thin dentin barrier. A sterile explorer was used to create pulp exposure in the center of the cavity floor. Bleeding of the pulp was controlled using sterile cotton pellets moistened with sterile saline until physiologic haemostasis occurred and then dried with cotton pellets. 


\section{Restoration of teeth:}

Direct pulp capping was done in each tooth according to its designated group. The materials were mixed and applied according to the manufacturer instructions. Thereafter, all cavities were filled entirely with a resin-modified glass ionomer cement (Vitrabond; 3M ESPE, St Paul, MN) and light-cured for 40 seconds to assure perfect sealing around the pulp. All the animals were injected with $24 \mathrm{~mL}$ of $10 \%$ dextrose serum subcutaneously to prevent side effects of general anesthesia during recoveries such as mortality/morbidity due to lack of appetite and glucosuria.

After 1 and 3 months, the animals were sacrificed with an anesthetic overdose. Vital perfusion with $10 \%$ formalin through the common carotid artery was performed. The teeth were extracted, fixed in $10 \%$ neutral buffered formalin solution and decalcified. The specimens were then embedded in paraffin, sectioned at an average thickness of 6 $\mu \mathrm{m}$, and stained with hematoxyline- eosin ${ }^{(30)}$. The results were evaluated by one evaluator using a light microscope, according to the criteria described below $^{(31)}$. Each histomorphological event was evaluated by numerical scores from 1 to 4 , with 1 being the best result and 4 the worst result.

I-Hard tissue dentin bridge

\section{A) Thickness of dentin bridge formation}

1. Above $250 \mu \mathrm{m}$.

2. From 150 to $249 \mu \mathrm{m}$.

3. From 1 to $149 \mu \mathrm{m}$.

4. Partial or absent bridge.

\section{B) Morphology of dentin bridge}

1. Regular pattern of dentinal tubules.

2. Regular pattern of dentinal tubules and irregular hard tissue.

3. Irregular pattern of dentinal tubules.

4. No tubules present, only hard tissue or no hard tissue.
II-Dental pulp

A) Intensity of inflammatory reaction of the dental pulp

1. Absent or very few cells.

2. Mild: average number less than 10 cells.

3. Moderate: average number of $10-25$ cells.

4. Severe: average number greater than 25 cells.

\section{B) Extension of the inflammatory reaction}

1. Absent: (No inflammatory cells)

2. Mild: inflammatory cells only next to dentin bridge or area of pulp exposition

3. Moderate: inflammatory cells are observed in part of the coronal pulp

4. Severe: all coronal pulp is infiltrated or necrosed.

Data was photographed, scored and statistically analyzed.

\section{Statistical Analysis}

Qualitative data was presented as frequencies and percentages. Fisher's Exact test was used for comparisons between the groups. Friedman's test was used to study the changes by time in qualitative variables. Numerical data were explored for normality by checking the distribution of data and using tests of normality (Kolmogorov-Smirnov and Shapiro-Wilk tests). Dentin bridge thickness data showed parametric (normal) distribution while inflammatory cell counts showed non-parametric (non-normal) distribution. Data was presented as mean and standard deviation (SD) values. For parametric data; repeated measures Analysis of Variance (ANOVA) was used to compare between the materials as well as to study the changes by time. Bonferroni's post-hoc test was used for pair-wise comparisons when ANOVA test is significant. For 
non-parametric data; Kruskal-Wallis test was used to compare between the materials while Wilcoxon signed-rank test was used to study the changes by time within each group. Dunn's test was used for pair-wise comparisons when Kruskal-Wallis test is significant. The significance level was set at $\mathrm{P} \leq$ 0.05 . Statistical analysis was performed with $\mathrm{IBM}^{\circledR}$ SPSS $^{\circledR}$ Statistics Version 20 for Windows.

\section{RESULTS:}

\section{I- Hard tissue dentin bridge}

\section{A) Thickness of dentin bridge formation}

After 1 month; there was a statistically significant difference between the groups $(P$-value $<0.001)$. NMTA group showed the statistically significantly highest mean dentin bridge thickness (Fig 1) followed by NCEM then MTA (Fig 2) and CEM, while BG group showed the statistically significantly lowest mean dentin bridge thickness.

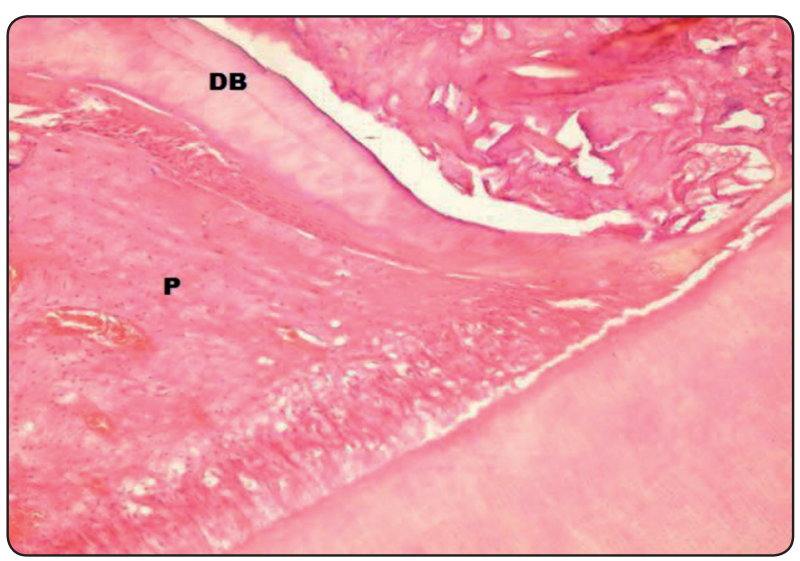

Fig (2): Photomicrograph of MTA treated group, showing thick dentin bridge (DB) at the exposure site and well organized pulp tissues (p) under formed reparative dentin at 1 month (H\&E. Mag x 400).

${ }^{\circledR}$ IBM Corporation, NY, USA.

${ }^{\circledR}$ SPSS, Inc., an IBM Company.
After 3 months; there was a statistically significant difference between the groups ( $P$-value $<0.001)$. There was no statistically significant difference between NMTA and NCEM groups (Fig 3 ); both showed the statistically significantly highest mean dentin bridge thickness values. Other groups showed the statistically significantly lowest mean dentin bridge thickness values with no statistically significant difference between them.

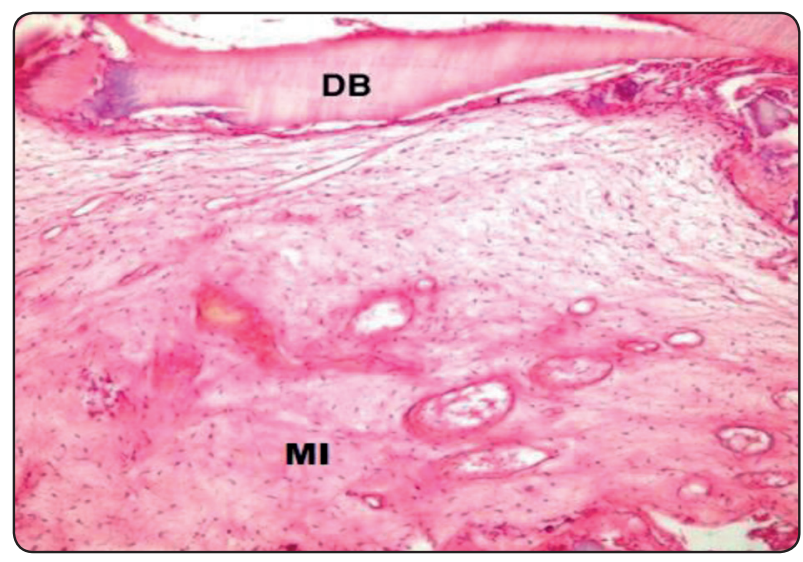

Fig (1): Photomicrograph of NMTA treated group, showing formation of dentin bridge(DB) at the exposure site and mild inflammatory reaction (MI) at 1month (H\&E. Mag $\mathrm{x} 200$ )

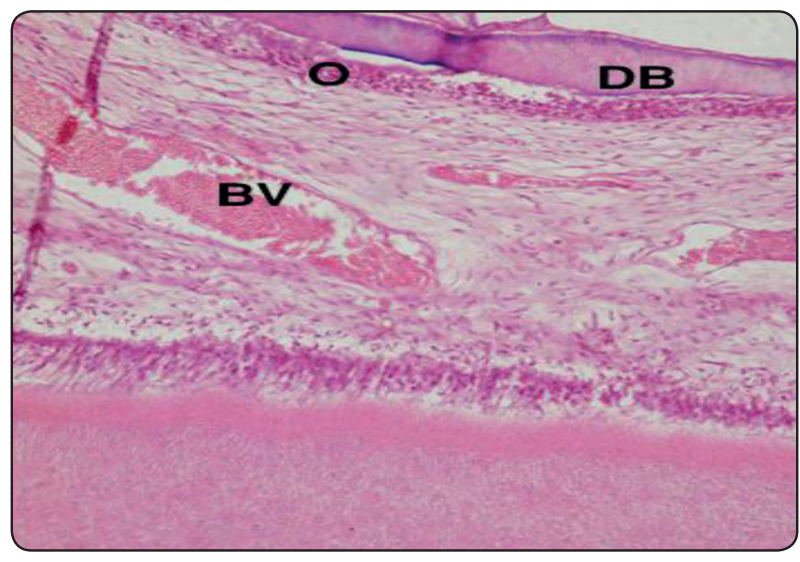

Fig (3):Photomicrograph of CEM treated group, showing formation of regular tubular dentin bridge (DB), Odontoblast like cells $(\mathrm{O})$ and no inflammatory reaction at 3 month, some blood vessels appeared dilated (BV) (H\&E. Mag x200) 
As regards the changes by time within each group; there was a statistically significant increase in mean dentin bridge thickness after 3 months in all groups (table 1).

\section{B) Morphology of dentin bridge}

After 1 month; there was a statistically significant difference between the groups $(P$-value $<0.001)$. NBG group showed the highest prevalence of no tubular dentin. NMTA, NCEM and BG groups showed the highest prevalence of irregular dentinal tubules pattern. Groups MTA and CEM showed the highest prevalence of regular dentinal tubules pattern. After 3 months; there was a statistically significant difference between the groups ( $P$-value $<0.001)$. The results for all groups were the same as at one month (table 2).

As regards the changes by time within each group; there was no statistically significant change in dentin bridge morphology after 3 months in all groups (table 3).

TABLE (1) The mean, standard deviation values and results of repeated measures ANOVA test for comparison between dentin bridge thickness in different groups as well as the changes by time

\begin{tabular}{|c|c|c|c|c|c|c|c|c|c|c|c|c|c|}
\hline \multirow{2}{*}{ Time } & \multicolumn{2}{|c|}{ MTA } & \multicolumn{2}{|c|}{ NMTA } & \multicolumn{2}{|c|}{ CEM } & \multicolumn{2}{|c|}{ NCEM } & \multicolumn{2}{|c|}{ BG } & \multicolumn{2}{|c|}{ NBG } & \multirow{2}{*}{$\begin{array}{c}P \text {-value } \\
\text { (Between } \\
\text { groups) }\end{array}$} \\
\hline & Mean & SD & Mean & SD & Mean & SD & Mean & $\mathrm{SD}$ & Mean & $\mathrm{SD}$ & Mean & SD & \\
\hline 1 month & $144.6^{\mathrm{C} \mathrm{C}}$ & 4.7 & $188.5^{\mathrm{A} \mathrm{A}}$ & 3.6 & $144.3^{\mathrm{C}} \mathrm{C}$ & 5.6 & $179.4^{\text {ВВ }}$ & 2.0 & $47.3^{\mathrm{E}}$ & 5.1 & $92.5^{\mathrm{D}}$ & 3.2 & $<0.001 *$ \\
\hline 3 months & $249.4^{\text {в в }}$ & 6.9 & $274.3^{\mathrm{A} A}$ & 4.2 & $238.3^{\text {в }}$ & 5.3 & $272.5^{\mathrm{AA}}$ & 12.4 & $229.9^{\text {вв }}$ & 28.7 & $231.1^{\mathrm{B}}$ & 7.6 & $<0.001 *$ \\
\hline $\begin{array}{c}P \text {-value } \\
\text { (Within group) }\end{array}$ & \multicolumn{2}{|c|}{$<0.001^{*}$} & \multicolumn{2}{|c|}{$<0.001 *$} & \multicolumn{2}{|c|}{$<0.001 *$} & \multicolumn{2}{|c|}{$<0.001 *$} & \multicolumn{2}{|c|}{$<0.001 *$} & \multicolumn{2}{|c|}{$<0.001 *$} & \\
\hline
\end{tabular}

*: Significant at $P \leq 0.05$, Different superscripts in the same row are statistically significantly different

TABLE (2). The frequencies (n), percentages and results of Fisher's Exact test for comparison between morphology of dentin bridges in the different groups after 1 month and 3 months.

\begin{tabular}{|c|c|c|c|c|c|c|c|c|c|c|c|c|c|}
\hline \multirow[b]{2}{*}{ Dentin bridge $(1 \mathrm{~m})$} & \multicolumn{2}{|c|}{ MTA } & \multicolumn{2}{|c|}{ NMTA } & \multicolumn{2}{|c|}{ CEM } & \multicolumn{2}{|c|}{ NCEM } & \multicolumn{2}{|c|}{ BG } & \multicolumn{2}{|c|}{ NBG } & \multirow{2}{*}{$P$-value } \\
\hline & $\mathrm{n}$ & $\%$ & $\mathrm{~N}$ & $\%$ & $\mathrm{n}$ & $\%$ & $\mathrm{n}$ & $\%$ & $\mathrm{n}$ & $\%$ & $\mathrm{n}$ & $\%$ & \\
\hline No tubules & 0 & 0.0 & 2 & 25.0 & 0 & 0.0 & 2 & 25.0 & 0 & 0.0 & 8 & 100.0 & \multirow{3}{*}{$<0.001 *$} \\
\hline Irregular pattern & 0 & 0.0 & 6 & 75.0 & 0 & 0.0 & 6 & 75.0 & 6 & 75.0 & 0 & 0.0 & \\
\hline \multirow[t]{2}{*}{ Regular pattern } & 8 & 100.0 & 0 & 0.0 & 8 & 100.0 & 0 & 0.0 & 2 & 25.0 & 0 & 0.0 & \\
\hline & \multicolumn{2}{|c|}{ MTA } & \multicolumn{2}{|c|}{ NMTA } & \multicolumn{2}{|c|}{ CEM } & \multicolumn{2}{|c|}{ NCEM } & \multicolumn{2}{|c|}{ BG } & \multicolumn{2}{|c|}{ NBG } & \multirow{2}{*}{$P$-value } \\
\hline Dentin bridge $(3 \mathrm{~ms})$ & $\mathrm{n}$ & $\%$ & $\mathrm{~N}$ & $\%$ & $\mathrm{n}$ & $\%$ & $\mathrm{n}$ & $\%$ & $\mathrm{n}$ & $\%$ & $\mathrm{n}$ & $\%$ & \\
\hline No tubules & 0 & 0.0 & 3 & 37.5 & 0 & 0.0 & 3 & 37.5 & 0 & 0.0 & 8 & 100.0 & \multirow{3}{*}{$<0.001 *$} \\
\hline Irregular pattern & 0 & 0.0 & 5 & 62.5 & 0 & 0.0 & 5 & 62.5 & 7 & 87.5 & 0 & 0.0 & \\
\hline Regular pattern & 8 & 100.0 & 0 & 0.0 & 8 & 100.0 & 0 & 0.0 & 1 & 12.5 & 0 & 0.0 & \\
\hline
\end{tabular}


TABLE (3) The frequencies (n), percentages and results of Friedman's test for comparison between morphology of dentin bridges at different follow up periods within each group

\begin{tabular}{|c|c|c|c|c|c|c|}
\hline \multirow{2}{*}{ Group } & \multirow[b]{2}{*}{ Dentin bridge } & \multicolumn{2}{|c|}{1 month } & \multicolumn{2}{|c|}{3 months } & \multirow{2}{*}{$P$-value } \\
\hline & & $\mathrm{n}$ & $\%$ & $\mathrm{n}$ & $\%$ & \\
\hline MTA & Regular pattern & 8 & 100.0 & 8 & 100.0 & $\mathrm{NC}^{\dagger}$ \\
\hline \multirow{2}{*}{ NMTA } & No tubules & 2 & 25.0 & 3 & 37.5 & \multirow{2}{*}{0.317} \\
\hline & Irregular pattern & 6 & 75.0 & 5 & 62.5 & \\
\hline CEM & Regular pattern No & 8 & 100.0 & 8 & 100.0 & $\mathrm{NC}^{\dagger}$ \\
\hline \multirow{2}{*}{ NCEM } & No tubules & 2 & 25.0 & 3 & 37.5 & \multirow{2}{*}{0.317} \\
\hline & Irregular pattern & 6 & 75.0 & 5 & 62.5 & \\
\hline \multirow{2}{*}{ BG } & Irregular pattern & 6 & 75.0 & 7 & 87.5 & \multirow{2}{*}{0.317} \\
\hline & Regular pattern & 2 & 25.0 & 1 & 12.5 & \\
\hline NBG & No tubules & 8 & 100.0 & 8 & 100.0 & $\mathrm{NC}^{\dagger}$ \\
\hline
\end{tabular}

*: Significant at $P \leq 0.05,{ }^{*}$ : Not computed because the variable is constant

\section{II- Dental pulp}

\section{A) Intensity of inflammatory reaction of the dental pulp}

After 1 month; there was a statistically significant difference between the groups $(P$-value $<0.001)$. NBG group showed the statistically significant highest mean value of inflammatory cell counts. NMTA, NCEM and BG groups showed statistically significantly lower mean values with no statistically significant difference followed by CEM group. MTA group showed the statistically significantly lowest mean value of inflammatory cell counts (table 4) (Fig 2).

After 3 months; there was a statistically significant difference between the groups $(P$-value $<0.001)$. NMTA, NCEM and NBG groups; all showed the statistically significantly highest mean inflammatory cell counts with no statistically significant difference between them. Followed by CEM and BG groups; both showed statistically significantly lower mean values while MTA group showed the statistically significantly lowest mean inflammatory cell counts values (No inflammatory cells) (table 4).

As regards the changes by time within each group; all groups showed a statistically significant decrease in mean inflammatory cell counts after 3 months, except
MTA group showed non-statistically significant change in mean inflammatory cell counts (table 4).

\section{B) Extension of the inflammatory reaction}

After 1 month; there was a statistically significant difference between the groups $(P$-value $<0.001)$. MTA group showed the highest prevalence of no inflammatory reaction (Fig 2) while NMTA group showed the highest prevalence of mild inflammatory reaction (Fig 1). NBG group was the only group to show severe inflammation.(table 5)

After 3 months; there was a statistically significant difference between the groups $(P$-value $<$ $0.001)$. MTA group showed the highest prevalence of no inflammation. NCEM group showed the highest prevalence of mild inflammation. Group BG was the only group with moderate inflammation. NBG group was the only group to show severe inflammation and tissue necrosis (table 5)(Fig 4).

As regards the changes by time within each group; groups MTA, CEM and BG showed nonstatistically significant change in extension of inflammation after 3 months. For NMTA and NCEM groups, there was a statistically significant decrease in extension of inflammation after 3 months. While for NBG group, there was a statistically significant increase in extension of inflammation from moderate and severe to severe and tissue necrosis (table 6). 
TABLE (4) The mean, standard deviation values and results of Kruskal-Wallis test and Wilcoxon signedrank test for comparison between inflammatory cell counts in the different groups as well as the changes by time

\begin{tabular}{|c|c|c|c|c|c|c|c|c|c|c|c|c|c|}
\hline \multirow[b]{2}{*}{ Time } & \multicolumn{2}{|c|}{ MTA } & \multicolumn{2}{|c|}{ NMTA } & \multicolumn{2}{|c|}{ CEM } & \multicolumn{2}{|c|}{ NCEM } & \multicolumn{2}{|c|}{ BG } & \multicolumn{2}{|c|}{ NBG } & \multirow{2}{*}{$P$-value } \\
\hline & Mean & SD & Mean & SD & Mean & $\mathrm{SD}$ & Mean & $\mathrm{SD}$ & Mean & $\mathrm{SD}$ & Mean & $\mathrm{SD}$ & \\
\hline 1 month & $0.9^{\mathrm{D}}$ & 0.5 & $23.3^{\text {в }}$ & 3.2 & $10.0^{\mathrm{C}}$ & 1.9 & $26.6^{\text {в }}$ & 2.2 & $27.5^{\text {в }}$ & 3.2 & $34.8^{\mathrm{A}}$ & 1.3 & $<0.001 *$ \\
\hline 3 months & $0.0^{\mathrm{C}}$ & 0.0 & $11.0^{\mathrm{A}}$ & 2.1 & $3.8^{\mathrm{B}}$ & 2.3 & $12.5^{\mathrm{A}}$ & 4.3 & $6.3^{\text {в }}$ & 0.5 & $13.8^{\mathrm{A}}$ & 3.5 & $<0.001 *$ \\
\hline$P$-value & \multicolumn{2}{|c|}{0.059} & \multicolumn{2}{|c|}{$0.012 *$} & \multicolumn{2}{|c|}{$0.011^{*}$} & \multicolumn{2}{|c|}{$0.011 *$} & \multicolumn{2}{|c|}{$0.011^{*}$} & \multicolumn{2}{|c|}{$0.011^{*}$} & \\
\hline
\end{tabular}

*: Significant at $P \leq 0.05$, Different superscripts in the same row are statistically significantly different

TABLE (5) The frequencies (n), percentages and results of Fisher's Exact test for comparison between inflammatory extensions in the different groups after 1 month and 3 months

\begin{tabular}{|c|c|c|c|c|c|c|c|c|c|c|c|c|c|}
\hline \multirow[b]{2}{*}{ Inflammation (1 m) } & \multicolumn{2}{|c|}{ MTA } & \multicolumn{2}{|c|}{ NMTA } & \multicolumn{2}{|c|}{ CEM } & \multicolumn{2}{|c|}{ NCEM } & \multicolumn{2}{|c|}{ BG } & \multicolumn{2}{|c|}{ NBG } & \multirow{2}{*}{$P$-value } \\
\hline & $\mathrm{n}$ & $\%$ & $\mathrm{~N}$ & $\%$ & $\mathrm{n}$ & $\%$ & $\mathrm{n}$ & $\%$ & $\mathrm{n}$ & $\%$ & $\mathrm{n}$ & $\%$ & \\
\hline No & 7 & 87.5 & 0 & 0.0 & 5 & 62.5 & 0 & 0.0 & 0 & 0.0 & 0 & 0.0 & \multirow{4}{*}{$<0.001 *$} \\
\hline Minimal & 1 & 12.5 & 7 & 87.5 & 3 & 37.5 & 5 & 62.5 & 5 & 62.5 & 0 & 0.0 & \\
\hline Moderate & 0 & 0.0 & 1 & 12.5 & 0 & 0.0 & 3 & 37.5 & 3 & 37.5 & 3 & 37.5 & \\
\hline Severe & 0 & 0.0 & 0 & 0.0 & 0 & 0.0 & 0 & 0.0 & 0 & 0.0 & 5 & 62.5 & \\
\hline & \multicolumn{2}{|c|}{ MTA } & \multicolumn{2}{|c|}{ NMTA } & \multicolumn{2}{|c|}{ CEM } & \multicolumn{2}{|c|}{ NCEM } & \multicolumn{2}{|c|}{ BG } & \multicolumn{2}{|c|}{ NBG } & \\
\hline $\operatorname{Inflammation}(3 \mathrm{~ms})$ & $\mathrm{n}$ & $\%$ & $\mathrm{~N}$ & $\%$ & $\mathrm{n}$ & $\%$ & $\mathrm{n}$ & $\%$ & $\mathrm{n}$ & $\%$ & $\mathrm{n}$ & $\%$ & $P$-value \\
\hline No & 8 & 100.0 & 5 & 62.5 & 7 & 87.5 & 2 & 25.0 & 0 & 0.0 & 0 & 0.0 & $<0.001 *$ \\
\hline Minimal & 0 & 0.0 & 3 & 37.5 & 1 & 12.5 & 6 & 75.0 & 5 & 62.5 & 0 & 0.0 & \\
\hline Moderate & 0 & 0.0 & 0 & 0.0 & 0 & 0.0 & 0 & 0.0 & 3 & 37.5 & 0 & 0.0 & \\
\hline Severe & 0 & 0.0 & 0 & 0.0 & 0 & 0.0 & 0 & 0.0 & 0 & 0.0 & 3 & 37.5 & \\
\hline Necrosis & 0 & 0.0 & 0 & 0.0 & 0 & 0.0 & 0 & 0.0 & 0 & 0.0 & 5 & 62.5 & \\
\hline
\end{tabular}


TABLE (6) The frequencies (n), percentages and results of Friedman's test for comparison between inflammatory extension at different follow up periods within each group

\begin{tabular}{|c|c|c|c|c|c|c|}
\hline \multirow{2}{*}{ Group } & \multirow[b]{2}{*}{ Inflammation } & \multicolumn{2}{|c|}{1 month } & \multicolumn{2}{|c|}{3 months } & \multirow{2}{*}{$P$-valuc } \\
\hline & & $\mathrm{n}$ & $\%$ & $\mathrm{n}$ & $\%$ & \\
\hline \multirow{2}{*}{ MTA } & No & 7 & 87.5 & 8 & 100.0 & \multirow{2}{*}{0.317} \\
\hline & Minimal & 1 & 12.5 & 0 & 0.0 & \\
\hline \multirow{3}{*}{ NMTA } & No & 0 & 0.0 & 5 & 62.5 & \multirow{3}{*}{$0.014 *$} \\
\hline & Minimal & 7 & 87.5 & 3 & 37.5 & \\
\hline & Moderate & 1 & 12.5 & 0 & 0.0 & \\
\hline \multirow{2}{*}{ CEM } & No & 5 & 62.5 & 7 & 87.5 & \multirow{2}{*}{0.157} \\
\hline & Minimal & 3 & 37.5 & 1 & 12.5 & \\
\hline \multirow{3}{*}{ NCEM } & No & 0 & 0.0 & 2 & 25.0 & \multirow{3}{*}{$0.025 *$} \\
\hline & Minimal & 5 & 62.5 & 6 & 75.0 & \\
\hline & Moderate & 3 & 37.5 & 0 & 0.0 & \\
\hline \multirow{3}{*}{ BG } & No & 0 & 0.0 & 0 & 0.0 & \multirow{3}{*}{1.000} \\
\hline & Minimal & 5 & 62.5 & 5 & 62.5 & \\
\hline & Moderate & 3 & 37.5 & 3 & 37.5 & \\
\hline \multirow{3}{*}{ NBG } & Moderate & 3 & 37.5 & 0 & 0.0 & \multirow{3}{*}{$0.014 *$} \\
\hline & Severe & 5 & 62.5 & 3 & 37.5 & \\
\hline & Tissue necrosis & 0 & 0.0 & 5 & 62.5 & \\
\hline
\end{tabular}

\section{*: Significant at $P \leq 0.05$}

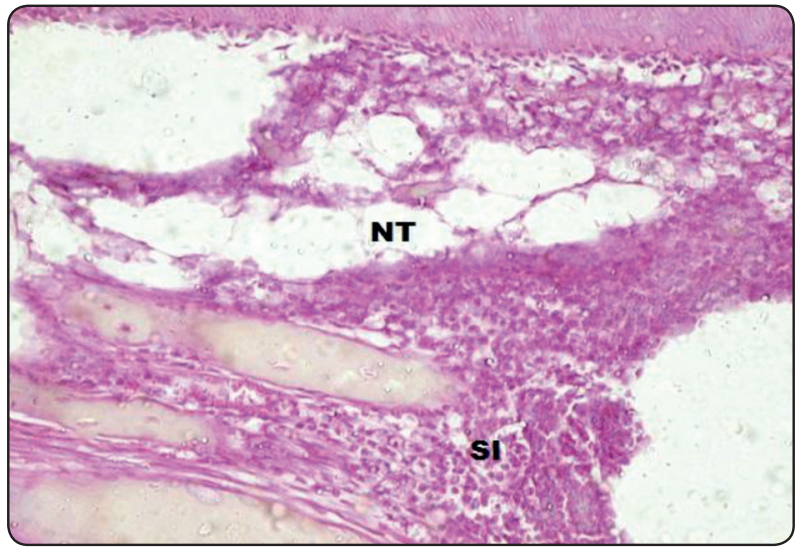

Fig. (4): Photomicrograph of NBG treated group, showing severe inflammatory reaction(SI) and degenerated pulp tissues at 3 month (H\&E. Mag x400).

\section{DISCUSSION}

Direct pulp capping has been practiced for more than 200 years. Dentists have used various dressing materials and techniques for direct pulp capping. Recently, it is of great importance to conduct minimally invasive dentistry and to keep the vitality of the young tooth and avoid root canal treatment if possible ${ }^{(32)}$. This study was designed to evaluate and compare the histological response of dog's pulp after direct pulp capping with 3 different materials; MTA, Bioactive glass, CEM and their nanoparticles, at 1 month and 3 month time intervals.

The histological investigation is the most critical evaluation method of pulp capping agents, in particular when the clinical criterion is inadequate 
and/or for judgment the efficacy of dressing materials regarding the presence or absence of inflammation and necrosis, in addition to the calcified bridge formation ${ }^{(33)}$. Dogs were chosen as experimental animals because of their dental similarities with human dentition bigger than those with rats and cats.

The histo-morphological data generated by this study regarding the formed dentin bridge showed that NMTA and NCEM induced thick dentin bridge with irregular dentin pattern in 1 and 3 months evaluation time period while MTA and CEM induced thinner dentin bridge with regular dentin pattern. These results were supported by several studies which confirmed that the induction of dentin bridge formation in CEM was comparable with that in MTA ${ }^{(34-36)}$. Asgary et al. ${ }^{(34)}$ indicated that when CEM cement and MTA were used for DPC, they caused a faster formation of a uniform hard tissue bridge (HTB). During the process of hydration, $\mathrm{CH}$ is formed; which has the ability to induce the formation of HTB. In addition, both MTA and CEM are able to stimulate dentinal bridge formation as they induced a high expression of fibronectin/ tenascin, two major components of the matrix of reparative dentine bridge, when they were used for direct pulp capping ${ }^{(37)}$.

Recent studies have concluded that nanomodification of MTA increased the surface area of the powder and the surface reaction resulting in better hydration of particles and more calcium hydroxide formation that increases its chemical reactivity ${ }^{(38,39)}$. Furthermore, the nanomodification of MTA increased the release of calcium ions in post setting time, which can significantly influence the induction of reparative dentin formation of human dental pulp cells ${ }^{(40)}$. This means that a given mass of material in a nanoparticles form is much more reactive than the same mass of material in its conventional form. These properties may explain the formation of thick dentin bridge with irregular dentinal tubules pattern in NMTA and NCEM.
BG and NBG groups showed the lowest mean dentin bridge thickness values with no tubular dentin pattern. These findings may be resulting from poor mechanical properties of bioactive glass, in particular, low fracture toughness, as most of the released ions might be transported away from the application site by body fluid before the formation of new hard tissue ${ }^{(41,42)}$. Also, it may be related to the release of $\mathrm{Ca}$ ions and alkalinity by $\mathrm{BG}$ and NBG at a lower rate than medications based on calcium hydroxide ${ }^{(43)}$. This was explained by the formation of a hydroxyapatite or apatite like layer (bio-mineralization) on the hydrated biomaterial surface which further stabilizes the biomaterial structure, preventing the overdose of component leaching in the medium ${ }^{(44)}$.

The results of the present study about the inflammatory reaction of the dental pulp to materials with conventional particle size; MTA displayed the highest prevalence of no inflammation followed by CEM while BG showed the highest prevalence of moderate inflammation and the highest inflammatory cell counts. These results were consistent with the histological results of earlier studies ${ }^{(45-47)}$. On the basis of their results, both MTA and CEM showed similar favorable inflammatory responses and biologic pulp tissue reactions. It was proved that CEM has a high alkalinity as MTA. This high alkalinity of both materials causes denaturation of adjacent cells, tissue proteins and a few bacteria that might be present in the exposed area. As the materials set, the $\mathrm{pH}$ changes and the cell injuries subside with an improvement of inflammatory condition $^{(48-50)}$. In addition, MTA and CEM have the ability to release calcium ions during setting, with the subsequent binding of calcium with phosphorus to form hydroxyapatite crystals ${ }^{(51)}$. This biomaterial is more likely to cause alterations in cellular enzymatic activity than to change the permeability, which facilitates healing ${ }^{(18)}$. Also, this compound was reported to be responsible for the bioactivity of MTA and CEM cements ${ }^{(52)}$. 
On the other hand, the reaction of NMTA and NCEM groups ranged from no inflammation to mild inflammation and moderate inflammation while NBG group was the only group showing severe inflammation and tissue necrosis. All nano groups showed the highest mean inflammatory cell counts at both evaluations time periods. This finding may be attributed to when our bodies exposed to several different types of nanoparticles molecules; it may induce unexpected tissue inflammation ${ }^{(53,54)}$. Likewise, some metallic nanoparticles, such as $\mathrm{SiO} 2$ and $\mathrm{TiO} 2$, strongly result in inflammation activation and induction of pro-inflammatory cytokine interleukin (IL)-1 $\beta$ while their micro sized particles had been considered to be biocompatible and rarely cause inflammation ${ }^{(55)}$. Moreover, this finding was in agreement with the results of a pervious study ${ }^{(56)}$, which concluded that CEM cement was superior to nanohydroxyapatite as a direct pulp capping agent when evaluating the rate of tertiary dentin formation, as well as, subsequential pulpal inflammation scores.

In the current study, both BG and NBG recorded the highest inflammatory cell counts in the two evaluating periods. This might be due to the pivotal role of $\mathrm{CaP}$ debris with surrounding tissue. As it was indicated that when biomaterial particles that have been generated from bulk materials interact with immune cells (PMNs, monocytes. . .), it leads to cell activation and the release of inflammatory mediators $^{(57)}$. Even though BG is capable of generating a carbonated hydroxyapatite layer, which corresponds structurally and chemically to the biological mineral of bone ${ }^{(58)}$, it was evidenced that HA wear debris is a potent stimulus for the release of a variety of cytokines when phagocytosed ${ }^{(59)}$.

\section{CONCLUSION}

Under the circumstances of this study, it can be concluded that:

- MTA and CEM are favorable materials for direct pulp capping.
- Nano sizing of materials tested enhanced the dentin bridge thickness, but of inferior quality than that of their conventional form.

- Nano particles of all materials recorded a higher inflammatory cell reaction, this reconfirms that the quality of the dentin bridge formed is more important than its thickness.

- Both BG and NBG were the lowest of all variables tested.

\section{ACKNOWLEDGMENT}

The authors would like to thank Prof. Sabry ElKorashy (professor of Inorganic Chemistry, Faculty of Science, Suez Canal University) and Dr. Enas Mahmoud Hegazy (lecturer in oral biology, Faculty of Dentistry, Suez Canal University) for their contribution and great effort in this study.

\section{REFERENCES}

1. Couve E. Ultrastructural changes during the life cycle of human odontoblasts. Arch Oral Biol 1986; 31: 643-651.

2. Pashley DH. Dynamics of the pulpo-dentin complex. Crit Rev Oral Biol Med 1996; 7: 104-133.

3. Bergenholtz G. Advances since the paper by Zander and Glass (1949) on the pursuit of healing methods for pulpal exposures: historical perspectives. Oral Surg Oral Med Oral Pathol Oral Radiol Endod 2005; 100: S102-S108.

4. ADA. 2005-2006 Survey of dental services rendered and distribution of dentists in the United States by region and state. Chicago: American Dental Association, Survey Center.

5. Fuks AB, Gavra S, Chosack A. Long-term follow up of traumatized incisors treated by partial pulpotomy. Pediatr Dent 1993;15:334-336.

6. Iwamoto CE, Adachi E, Pameijer CH, Barnes D, Romberg EE, Jefferies S.Clinical and histological evaluation of white ProRoot MTA in direct pulp capping. Am J Dent 2006;19:85-90.

7. Horsted P, Sandergaard B, Thylstrup A, El Attar K, Fejerskov O. A retrospective study of direct pulp capping with calcium hydroxide compounds. Endod Dent Traumatol 1985;1:29-34. 
8. Aguilar P, Linsuwanont P. Vital pulp therapy in vital permanent teeth with cariously exposed pulp: A systematic review. J Endod 2011;37:581-587.

9. Kakehashi S, Stanley HR, Fitzgerald RJ. The effects of surgical exposures of dental pulps in germ-free and conventional laboratory rats. Oral Surg Oral Med Oral Pathol. 1965;20:340-349.

10. Modena KC, Casas-Apayco LC, Atta MT, Costa CA, Hebling J, Sipert CR, et al. Cytotoxicity and biocompatibility of direct and indirect pulp capping materials. J Appl Oral Sci. 2009;17:544-554.

11. Hilton TJ. Keys to clinical success with pulp capping: A review of the literature. Oper Dent 2009; 34: 615-625.

12. Bogen G, Kim JS, Bakland LK. Direct pulp capping with mineral trioxide aggregate: an observational study. J Am Dent Assoc 2008; 139: 305-315.

13. Saberi EA, Karkehabadi H, Mollashahia NF. Cytotoxicity of various endodontic materials on stem cells of human apical papilla. Iran Endod J 2016; 11:17-22.

14. Hench LL. The story of Bioglass. J Mater Sci Mater Med 2006; 17:967-978.

15. Xynos ID, Edgar AJ, Buttery LDK, Hench LL, Polak JM. Ionic products of bioactive glass dissolution increase proliferation of human osteoblasts and induce insulin-like growth factor II MRNA expression and protein synthesis," Biochem Biophys Res Commun 2000; 276:461-465.

16. Hench LL. "Bioactive materials for gene control," new materials and technologies for healthcare, eds L. L. Hench, J. R. Jones and M. B. Fenn. World Scientific, Singapore, 2011, pp 25-48.

17. Stanley HR, Clark AE, Pameijer CH, Louw NP. Pulp capping with a modified bioglass formula (\#A68modified). Am J Dent 2001;14:227-232.

18. Utneja S, Nawal RR, Talwar S, Verma M. Current perspectives of bio-ceramic technology in endodontics: calcium enriched mixture cement-review of its composition, properties and applications. Restor Dent Endod 2015;40:1-13.

19. Asgary S, Nazarian H, Khojasteh A, Shokouhinejad N. Gene expression and cytokine release during odontogenic differentiation of human dental pulp stem cells induced by 2 endodontic biomaterials. J Endod 2014;40:387-392.

20. Mozayeni MA, Milani AS, Marvasti LA, Asgary S. Cytotoxicity of calcium enriched mixture cement compared with mineral trioxide aggregate and intermediate restorative material. Aust Endod J 2012;38:70-75.

21. Mehrdad L, Malekafzali B, Shekarchi F, Safi Y, Asgary S. Histological and CBCT evaluation of a pulpotomised primary molar using calcium enriched mixture cement. Eur Arch Paediatr Dent 2013;14:191-194.

22. Haghgoo R, Arfa S, Asgary S. Microleakage of CEM Cement and ProRoot MTA as Furcal Perforation Repair Materials in Primary Teeth. Iran Endod J 2013;8:187-190.

23. Khorakian F, Mazhari F, Asgary S, Sahebnasagh M, Alizadeh Kaseb A, Movahhed T, Sarraf Shirazi AR. Twoyear outcomes of electrosurgery and calcium-enriched mixture pulpotomy in primary teeth: a randomised clinical trial. Eur Arch Paediatr Dent 2014;15:223-228.

24. Asgary S, Eghbal MJ, Ghoddusi J, Yazdani S. One-year results of vital pulp therapy in permanent molars with irreversible pulpitis: an ongoing multicenter, randomized, non-inferiority clinical trial. Clin Oral Investig 2013;17:431-439.

25. Mitra SB, Wu D, Holmes, B. N. An application of nanotechnology in advanced dental materials. J Am Dent Assoc 2003;134: 1382-1390.

26. Tschoppe P,Zandim DL, Martus P, Kielbassa AM. Enamel and dentine remineralization by nanohydroxyapatite toothpastes. J Dent 2011; 39: 430-437.

27. Xavier JR, Desai P, Varanasi VG, Al-Hashimi I, Gaharwar AK. Advanced Nanomaterials: Promises for improved dental tissue regeneration. In: Anil, editor. Nanotechnology in Endodontics: Current and potential Clinical Applications. 1st ed. Switzerland: Springer International Publishing; 2015. p.5-22.

28. Nezafati N, Moztarzadeh F,Mozafari M. In vitro evaluations of a mechanically optimized calcium phosphate cement as a filler for bone repair. Key Eng Mater 2012; 209-214.

29. Hong Z, Reis RL, Mano J F. Preparation and in vitro characterization of novel bioactive glass ceramic nanoparticles. J Biomed Mater Res 2009;88: 304-313.

30. Sabeti MA, Nekofar M, Motahhary P, Ghandi M, Simon JH. Healing of apical periodontitis after endodontic treatment with and without obturation in dogs. J Endod 2006;32:628-633.

31. Faraco-Junior IM, Holland R. Histomorphological response of dogs' dental pulp capped with white mineral trioxide aggregate. Braz Dent J 2004; 15:104-108. 
32. Brodén J, Heimdal H, Josefsson O, Fransson H. Direct pulp capping procedures versus root canal treatment in young permanent vital teeth with pulp exposure due to caries. A systematic review American Journal of Dentistry 2016; 29: 4-9.

33. Aeinehchi M, Eslami B, Ganbariha M, Saffar AS. Mineral trioxide aggregate (MTA) and calcium hydroxide as pulp capping agents in human teeth: a preliminary report. Int Endod J 2003; 36:225-231.

34. Asgary S, Eghbal MJ, Parirokh M, Ghanavati F, Rahimi H. A comparative study of histologic response to different pulp capping materials and a novel endodontic cement. Oral Surg Oral Med Oral Pathol Oral Radiol Endod. 2008;106:609-614.

35. Tabarsi B, Parirokh M, Eghbal MJ, Haghdoost AA, Torabzadeh H, Asgary S. A comparative study of dental pulp response to several pulpotomy agents. Int Endod J 2010;43:565-571

36. Nosrat A, Seifi A, Asgary S. Pulpotomy in cariesexposed immature permanent molars using calciumenriched mixture cement or mineral trioxide aggregate: A randomized clinical trial. Int J Paediatr Dent 2012; 23(1):56-63.

37. Zarrabi MH, Javidi M, Jafarian AH, Joushan B. Immunohistochemical expression of fibronectin and tenascin in human tooth pulp capped with mineral trioxide aggregate and a novel endodontic cement. J Endod 2011;37:1613-1618.

38. Saghiri MA, Asgar K, Lotfi M, Garcia-Godoy F. Nanomodification of mineral trioxide aggregate for enhanced physiochemical properties. Int Endod $J$ 2012;45:979-988.

39. Bernardi A, Bortoluzzi EA, Felippe WT, Felippe MCS, Wan WS, Teixeira CS. Effects of the addition of nanoparticulate calcium carbonate on setting time, dimensional change, compressive strength, solubility and $\mathrm{pH}$ of MTA. Int Endod J 2017;50: 97-105.

40. Saghiri MA ${ }^{1}$, Asatourian A, Orangi J, Lotfi M, Soukup JW, Garcia-Godoy F, Sheibani N.Effect of particle size on calcium release and elevation of $\mathrm{pH}$ of endodontic cements. Dent Traumatol. 2015 Jun;31(3):196-201.

41. Jones, J.R., Lin, S., Yue, S., Lee, P.D., Hanna, J.V., Smith, M.E., Newport, R.J.: Bioactive glass scaffolds for bone regeneration and their hierarchical characterisation. Proc. Inst. Mech. Eng. Part H J. Eng. Med. 2010; 224: 1373-1387.
42. Jiang, P., Lin, H., Xing, R., Jiang, J., Qu, F.: Synthesis of multifunctional macroporous-mesoporous $\mathrm{TiO} 2-$ bioglasses for bone tissue engineering. J. Sol-Gel. Sci. Technol. 2012;61: 421-428.

43. Sharaan M and Fayyad D. Nanoparticles: Do they affect the physicochemical properties of biomaterials of Biodentine and Bioactive glass? ENDO 2017;11:1-8.

44. Gronthos S, Zannettino A, Hay S, Shi S, Graves SE, Kortesidis A, et al. Molecular and cellular characterization of highly purified stromal cells derived from human bone marrow. J Cell Sci 2003;116: 1827-1835.

45. Samiee M, Eghbal MJ, Parirokh M, Abbas FM, Asgary S. Repair of furcal perforation using a new endodontic cement. Clin Oral Investig. 2010;6:653-658.

46. Parirokh M, Mirsoltani B, Raoof M, Tabrizchi H, Haghdoost AA. Comparative study of subcutaneous tissue responses to a novel root-end filling material and white and grey mineral trioxide aggregate. Int Endod J. 2011;44:283-289.

47. Rahimi S, Mokhtari H, Shahi S,Kazemi A,Asgary S, Eghbal MJ, Mesgariabbasi M, Mohajeri D. Osseous reaction to implantation of two endodontic cements: Mineral trioxide aggregate (MTA) and calcium enriched mixture (CEM) Med Oral Patol Oral Cir Bucal. 2012;17:907-911.

48. Saidon J, He J, Zhu Q, Safavi K, Spangberg LSW. Cell and tissue reactions to mineral trioxide and Portland cement. Oral Surg Oral Med Oral Pathol Oral Radiol Oral Endod 2003; 95:483-489.

49. Asgary S., Shahabi S., Jafarzadeh T., Amini S., Kheirieh $\mathrm{S}$. The properties of a new endodontic material. J. Endod. 2008;34(8):990-993.

50. Amini Ghazvini S., Abdo Tabrizi M., Kobarfard F., Akbarzadeh Baghban A., Asgary S. Ion release and $\mathrm{pH}$ of a new endodontic cement, MTA and Portland cement. Iran. Endod. J. 2009;4:74-78.

51. Asgary S, Eghbal MJ, Parirokh M, Ghoddusi J. Effect of two storage solutions on surface topography of two root end fillings. Aust Endod J 2009;35:147-152.

52. Tay FR. Bioactivity of mineral trioxide aggregate and mechanism of action. In: Josette Camilleri (Ed). Mineral trioxide aggregate in dentistry: from preparation to application. Spring-Verlag, Berlin Heidelberg. 2014; 4: 61-85.

53. Yazdi AS, Guarda G, Riteau N, Drexler SK, Tardivel A, Couillin I, Tschopp J.Nanoparticles activate the NLR pyrin 
domain containing 3 (Nlrp3)inflammasome and cause pulmonary inflammation through release of IL-1alpha and IL1beta. Proc Natl Acad Sci U S A. 2010;107:19449-1954.

54. Baron L, Gombault A, Fanny M, Villeret B, Savigny F, Guillou N, Panek C, Le Bert M, Lagente V, Rassendren F, Riteau N, Couillin I. The NLRP3 inflammasome is activated by nanoparticles through ATP, ADP and adenosine. Cell Death Dis. 2015; 6:1629- 1637.

55. Kusaka T, Nakayama M, Nakamura K, Ishimiya M, Furusawa E, Ogasawara K. Effect of silica particle size on macrophage inflammatory responses. PLoS One. 2014;9:92634-92641.

56. Roza Haghgoo, Saeed Asgary, Fatemeh Mashhadi Abbas, and Roshanak Montazeri Hedeshi. Nano-Hydroxyapatite and Calcium-Enriched Mixture for Pulp Capping of Sound Primary Teeth: A Randomized Clinical Trial Iran Endod J. 2015; 10: 107-111.

57. Hallab NJ, Jacobs JJ. Biologic effects of implant debris. Bull Hosp Jt Dis 2009;67:182-188.

58. Khvostenkoa D, Hiltonb TJ, Ferracaneb JL, Mitchellc JC, Kruzica JJ. Bioactive glass fillers reduce bacterial penetration into marginal gaps for composite restorations. Dent Mater 2016;32: 73-81.

59. Bloebaum RD, Beeks Dorr LD, Savory CG, DuPont JA, Hofmann AA.Complications with hydroxyapatite particulate separation in total hiparthoplasty. Clin Orthop 1994;298:19-26. 